\title{
Physical Examination and Magnetic Resonance Imaging of Stress-Related Bone Injuries in Tuber Ischiadicum
}

\author{
Claes-Goran Sundell ${ }^{1 *}$, Lars Adin², Karin Larsen ${ }^{3}$ \\ 1.Claes-Goran Sundell, Department of Community Medicine and Rehabilitation Sports Medicine Unite, University, Umea, Sweden. \\ 2.Lars Adin, Pitea Hospital, Department of Radiology, Pitea, Sweden. \\ 3Karin Larsen, The Swedish school of Sport and health sciences, Dean's office, Stockholm, Sweden
}

Received: October 22, 2016; Accepted: December 29, 2016; Published: January 20, 2017

*Corresponding author: Claes-GoranSundell, Department of community medicine and Rehabilitation, Umea University 90187 Umea, Tel: +46706870775; E-mail: claes.g.s@telia.com

\section{Abstract}

Introduction: Stress-Related Bone Injuries (SRBI) in the Tuber Ischiadicum (TI) is a possible preliminary diagnosis in adolescent athletes with pain in the pelvic region or in the back of the thigh. The condition requires an early diagnosis in order to heal properly. We describe five cases of young athletes seeking a physiotherapist for pelvic or back thigh pain.

Materials and methods: Five patients previously diagnosed with lower back pain, groin pain, pelvic or back thigh pain underwent a Physical Examination (PE) by a physiotherapist to identify the pathogenesis of the pain. The PE led to the preliminary diagnosis of SRBI in the TI, which was confirmed by an MRI. The patients were treated with rest and Personally Guided Rehabilitation (PGR).

Results : All cases had a positive eccentric hip extension test and pain provocation on palpation on the TI. MRI found different levels of stress reactions/fractures in the enthesis of the TI. After rest and rehabilitation, all subjects returned to their previous level of physical activity.

Conclusion: PE appeared to identify adolescent athlete patients with SRBI in the TI requiring an MRI. The correct diagnosis led to a quick return to the previous level of physical activity.

Clinical relevance: An early and correct diagnosis thru a thorough PE can lead to complete healing and a return to sports.

Keywords: Tuber ischiadicum, stress reaction, stress fracture, Physical Examination

\section{Introduction}

In adolescent athletes with pain in the pelvic region, the symptoms need early recognition [1]. There are many commonly used differential diagnoses such as pain from SI joint, lower back lesions, and muscle strains and sprains $[1,2,3,4]$. The site of the muscles and tendon attachments in the skeleton, and the stress reactions or stress fractures in the enthesis of the pelvic girdle, can be the site of pain $[1,5,6]$. The growing skeleton is vulnerable when load is present, and both acute overload and overuse can be the background of enthesis injuries since there is a large amount of stress concentrated at this sites [1, 7].Anatomically, M. semimembranosus, M. semitendinosus, $M$. biceps femoris long head and M.Adductor Magnus, inserts with entheses in the TI and produce a large load to the pelvic bone area. Early diagnosis is important as recovery can be delayed due to the absence of, or inappropriate treatment [7].

Purpose: To describe five cases of SRBI in the TI, the PE of the condition, MRI, treatment and outcome.

\section{Materials and Methods}

Five patients previously diagnosed with lower back pain, groin pain, pelvic or back thigh pain and treated for these conditions, without recovery, came for a second opinion. They underwent a Physical Examination (PE) by a physiotherapist and MRI investigation to identify the pathogenesis of the pain.

After anamnesis was taken, a PE was performed with an eccentric test of the insertion of the hamstrings muscles with hip flexion $>100$ degrees, slightly flexed knee, and pain provocation when palpating the TI insertion of the hamstring muscles. The eccentric test was scored as positive if pain in TI was recognized as a symptom by the patient. The palpation test was also considered positive if the patient recognized the pain in TI as a symptom.

An MRI was performed on 1.5 Tesla Philips Achiva system using sequences for both good anatomical resolution and sequences with high sensitivity for water in order to depict oedema and bleeding in bone marrow and surrounding soft tissue. A radiologist with extensive experience of MRI read the examinations.

\section{Subjects}

Four boys (five cases), 13, 14, 15 (cases IVa and IVb),and 17 years old visited a physiotherapist due to pain in the back of the thigh during or after athletic performance. [Table1]

Case I: The first case was a 17-year-old football player who at the time of the first PE had experienced pain in the back of 
his leg for two months. He tried to return to athletic activity but immediately re-injured during explosive activities. The PE was performed before an MRI, which displayed a stress reaction (oedema) in the skeleton on the TI and in the surrounding soft tissues. He was recommended a 6-day rest, PGR for 20 weeks and stepwise increased physical exercise load that allowed him return to normal physical activity during this period.

Case II: A 14-year-old ice-hockey player who during a sprint competition felt pain in the back of his right thigh. After a PE and an MRI, an avulsion fracture in the tuber ischiadicum was diagnosed with a diastasis of about $15 \mathrm{~mm}$. He had a 3-day rest followed by a PGR for 11 weeks with a stepwise return to normal physical activity.

Case III: A 13-year-old track and field athlete experienced pain in the back of his leg during explosive training. After PE, an MRI displayed a stress reaction/oedema in the skeleton and a discrete reaction in the surrounding soft tissues. The treatment was 5 -week rest and PGR for 4weeks, followed by a stepwise return to normal physical activity

Case IV a: A 15-year-old ice-hockey player in an elite junior team with practice on and off ice, first presented in March 2008 with problems in his hamstring muscle on the right side without any description of sudden pain. He was diagnosed with a stress reaction on the TI, after a PE and MRI. The MRI examination showed a stress reaction (a large oedema) in the skeleton in the $\mathrm{TI}$ and a discrete reaction in the surrounding soft tissues. In a reinvestigation with MRI, one month later the oedema was found to be smaller with a discrete difference between left and right side. The treatment consisted of rest for three weeks and PGR during eight weeks with a stepwise return to normal physical activity.

Case IV b: The same patient as above, a 15-year-old icehockey player in an elite junior team with practice on and off the ice returned 9months later in December, the same year with similar problems but this time in his left leg. He had a PE and a third MRI examination, the first time for the second trauma. The MRI showed that the first oedema in the right TI had healed completely but a new stress reaction (large oedema) in the TI of the left side was found. The treatment consisted of two-week rest followed by a 6-weekPGR, and a stepwise return to normal physical activity

\section{Results}

In all cases, previous clinical examinations performed by different health care professionals suggested a strain or sprain of the hamstring muscles, low back lesions or SI joint problems. The clinical presentations were the same in all five cases. After a careful PE, the preliminary diagnoses were injuries to the enthesis of the TI. MRIs confirmed the clinical diagnoses and showed an oedema in the TI where the hamstring muscle has its insertion. In some cases, changes in the soft tissues surrounding in the TI were found [Table 1]

The PGR was used during different time spans ( 9 - 20 weeks). They were all followed up with the same PE as in the first examination to ensure that their progress was as expected (i.e. reduced pain). After PGR, all athletes were fully recovered with negative tests in the physical examination and with a return to the same physical activity level as before the injury [Table 1].

\section{Discussion}

Early diagnosis is important in cases of stress reaction or stress fractures in the tuber ischiadicum of the pelvic girdle, as recovery can be delayed due to the absence of, or incorrect diagnosis and treatment [1]. It is therefore important to distinguish between diagnoses in the pelvic region, which may be challenging, as there can be different sources of pain. Many different diagnoses in this region have been confirmed in the literature, such as pain from SI joint, lower back lesions, muscle strains and sprains $[1,2,3,4]$. The TI has been found to be a site of stress reactions, stress fractures and avulsion fractures resulting in pain in this region[1].

There is an opinion that during adolescence, the skeleton is more vulnerable than the tendons and muscles [7, 8]. Frequency and/or excessive load to the growing skeleton can result in an SRBI and pain as symptoms [5]. Stress reactions or stress fractures in the enthesis in the pelvic girdle skeleton can therefore indicate the site of the pelvic pain $[5,7,8,9,10]$. This stress reaction or stress fracture has a better tendency to heal if recognized early [7].

Askling showed the complexity of hamstring injuries in adult subjects and the importance of making the right diagnosis for treatment and prognosis of healing time [4]. Adolescent athletes have a more vulnerable skeleton than adults, which can result in stress reactions/stress fractures instead of tendon injuries [5]. In our five cases, the diagnoses were a mistake, when the subjects previously sought care. They were diagnosed with hamstring injury, lower back pain or SI joint pain. Conservative treatment such as manual therapy to the SI joint or the lower back, eccentric training or stretching, had no effect. Two physical tests resulted in a clinical diagnosis, and together with an anamnesis of sudden pain during physical activity or delayed pain after physical activity, an MRI examination confirmed the clinical diagnosis of SRBI in the TI enthesis of the pelvic girdle. In the literatures, there are discussions about SRBI on the TI enthesis, but to our knowledge, no suggestion is given to how to perform a PE in these cases. This study shows that it can be possible to diagnose the stress reaction or stress fracture in the enthesis with a PE. Ultrasound scanning can also be a tool for early diagnosis in this condition $[1,8]$.

Conclusions: There is a possibility to clinically diagnose patients with SRBI and distinguish between injuries in the lower back, SI joint, muscle tendons or muscle bellies in the back of the thigh and SRBI in the enthesis of the TI, before an MRI has verified the diagnosis. However, it needs to confirm the results of the PE and to exclude the possibility that the MRI findings are due to normal growth, by also performing an MRI on controls.

Recommendations: This is a small-size case study and we therefore recommend larger-size studies with a focus on physical examination. There is also a possibility of supplementing the physical examination by an ultrasound scan to strengthen the early diagnosis and therefore start early treatment followed by PGR to recovery. 


\begin{tabular}{|c|c|c|c|c|c|}
\hline Case & Case I & Case II & Case III & Case IVa & Case IVb \\
\hline Gender/Age & Male/17 & Male/14 & Male/13 & Male/15 & Male/15 \\
\hline Main Sport & Football & Ice hockey & Track and field & Ice hockey & Ice hockey \\
\hline Injury activity & Playing football & Explosive running & Explosive running & Ice hockey & Ice hockey \\
\hline Symptom & Pain back of thigh & Pain back of thigh & Pain back of thigh & $\begin{array}{c}\text { Pelvic pain, } \\
\text { Pain back of thigh right } \\
\text { side }\end{array}$ & $\begin{array}{c}\text { Groin pain, } \\
\text { Pain back of thigh left } \\
\text { side }\end{array}$ \\
\hline Previous PE & & & $\begin{array}{l}\text { Back pain, } \\
\text { sprain tight }\end{array}$ & & Groin injury \\
\hline Initial PE a, b & $a+b$ & $a+b$ & $a+b$ & $a+b$ & $a+b$ \\
\hline MRI affected side & $\begin{array}{l}\text { Stress reaction } \\
\text { (oedema) in the } \\
\text { skeleton in tuber } \\
\text { ischiadicum and in } \\
\text { surrounding soft } \\
\quad \text { tissues }\end{array}$ & $\begin{array}{l}\text { Avulsion fracture on } \\
\text { tuber ischiadicum } 15 \\
\text { mm diastasis }\end{array}$ & $\begin{array}{l}\text { Stress reaction oedema } \\
\text { in the skeleton on } \\
\text { tuber ischiadicum, and } \\
\text { discrete reaction in } \\
\text { the surrounding soft } \\
\text { tissues }\end{array}$ & $\begin{array}{l}\text { Stress reaction (great } \\
\text { oedema)in the skeleton } \\
\text { in tuber ischiadicum } \\
\text { and discrete reaction } \\
\text { in the surrounding soft } \\
\text { tissues }\end{array}$ & $\begin{array}{l}\text { Stress reaction (great } \\
\text { oedema) in the skeleton } \\
\text { in tuber ischiadicum. }\end{array}$ \\
\hline MRI contralateral side & No reaction & No reaction & No reaction & No reaction & $\begin{array}{l}\text { No reaction. } \\
\text { c Left TI healed }\end{array}$ \\
\hline Rest time & 6 days & 3 days & 5 weeks & 3 weeks & 2 weeks \\
\hline Rehabilitation & $\begin{array}{c}\text { Controlled } \\
\text { rehabilitation } 20 \text { weeks. } \\
\text { Stepwise return to } \\
\text { normal physical activity }\end{array}$ & $\begin{array}{c}\text { Controlled } \\
\text { rehabilitation } 11 \text { weeks } \\
\text { Stepwise return to } \\
\text { normal physical activity }\end{array}$ & $\begin{array}{c}\text { Controlled } \\
\text { rehabilitation } 4 \text { weeks. } \\
\text { Stepwise return to } \\
\text { normal physical activity }\end{array}$ & $\begin{array}{c}\text { Controlled } \\
\text { rehabilitation } 9 \text { weeks. } \\
\text { Stepwise return to } \\
\text { normal physical activity }\end{array}$ & $\begin{array}{l}\text { Controlled } \\
\text { rehabilitation } 7 \text { weeks. } \\
\text { Stepwise return to } \\
\text { normal physical activity }\end{array}$ \\
\hline Final PE a, b & $\mathrm{a}+\mathrm{b}$ negative & $\mathrm{a}+\mathrm{b}$ negative & $\mathrm{a}+\mathrm{b}$ negative & $\mathrm{a}+\mathrm{b}$ negative & $\mathrm{a}+\mathrm{b}$ negative \\
\hline Outcome & $\begin{array}{l}\text { Back to normal sport } \\
\text { activity }\end{array}$ & $\begin{array}{l}\text { Back to normal sport } \\
\text { activity }\end{array}$ & $\begin{array}{l}\text { Back to normal sport } \\
\text { activity }\end{array}$ & $\begin{array}{l}\text { Back to normal sport } \\
\text { activity }\end{array}$ & $\begin{array}{l}\text { Back to normal sport } \\
\text { activity }\end{array}$ \\
\hline \multicolumn{6}{|c|}{$\begin{array}{l}\text { PE }=\text { Physical examination } \\
\text { a. Eccentric test hamstrings with hip flexion> } 100 \text { and slightly flexed knee - eccentric test with positive pain provocation recognized as a symptom by } \\
\text { patient } \\
\text { b. Pain provocation when palpating tuber ischiadicum insertion. Hamstring muscles recognized as a symptom by patient } \\
\text { c. In the second MRI of the TI we could see that the first injury was completely healed }\end{array}$} \\
\hline
\end{tabular}

\section{Declarations}

\section{Ethical Approval}

The investigation was approved by the regional ethics committee at the Umea University (06-014).

\section{Clinical trial registration}

The investigation was approved by the regional ethics committee at the Umea University (2011/36-32M added to 06014M). Written consent has been obtained.

\section{References}

1. Brittenden J, Robinson P. Imaging of pelvic injuries in athletes. $\mathrm{Br} \mathrm{J}$ Radiol. 2005;78(929):457-468. doi:10.1259/bjr/73355272.

2. Hazle CR, Nitz AJ. Evidence-based assessment and diagnosis of pelvic girdle disorders: a proposal for an alternate diagnostic category. Physical Therapy Reviews. 2008;13(1):25-36: doi: $10.1179 / 174328808 \times 251975$

3. McGrath MC. Clinical considerations of sacroiliac joint anatomy: a review of function, motion and pain. Journal of Osteopathic Medicine. 2004;7(1):16-24

4. Askling C, Saartok T, Thorstensson A. Type of acute hamstring strain affects flexibility, strength, and time to return to pre- injury level. $\mathrm{Br} \mathrm{J}$ Sports Med. 2006;40(1):40-44. doi: 10.1136/bjsm.2005.018879.

5. Rossi F, Dragoni S. Acute avulsion fractures of the pelvis in adolescent competitive athletes: prevalence, location and sports distribution of 203 cases collected. Skeletal Radiol. 2001;30(3):127-131.

6. Benjamin M, Kaiser E, Milz S. Structure-function relationships in tendons: a review, J. Anat. 2008;212(3):211-228. doi: 10.1111/j.14697580.2008.00864.x

7. Ferlic PW, Sadoghi P, Singer G, Kraus T, Eberl R. Treatment for ischial tuberosity avulsion fractures in adolescent athletes. Knee Surg Sports TraumatolArthroc. 2014;22(4):893-897: doi 10.1007/s00167-0132570-4.

8. Lazrovic D, Wegner U, Peters G, Gossé F. Ultrasound for diagnosis of apophyseal injuries. Knee Surg, Sports Traumatol, Arthroscopy. 1996;3(4):234-237.

9. Yamamoto T, Akisue T, Nakatani T, Kawamoto T, Hitora T, Marui T, et.al. Apophysitis of the ischial tuberosity mimicking a neoplasm on magnetic resonance imaging. Skeletal Radiol. 2004;33(12):737-740. doi: 10.1007/s00256-004-0806-6.

10. Hong RJ, Hughes TH, Gentili A, Chung CB. Magnetic resonance imaging of the hip. Journal of magnetic resonance imaging. 2008;27(3):435445. doi: 10.1002/jmri.21124. 